\title{
Un poeta modernista olvidado: Carlos Pezoa Véliz (1879-1908)
}

I. Acaba de aparecer en Chile una nueva antología de Carlos Pezoa Véliz, con prólogo y notas del señor Nicomedes Guzmán. ${ }^{1}$ Desde la publicación de Poesias y prosas completas de Carlos Pezoa Véliz, recopilación y estudio de Armando Donoso, ${ }^{2}$ se han ocupado del poeta Raúl Silva Castro, Arturo Torres-Rioseco, Norberto Pinilla y Roberto Meza Fuentes. En I95x el Sr. Antonio de Undurraga le dedicó un estudio de 300 páginas. ${ }^{3}$ Antes de la edición de Donoso existía solamente la primera edición de su obra preparada por Ernesto Montenegro. ${ }^{4}$ A ella habrá que volver siempre ya que contiene lo más substancial de la obra de Pezoa.

Esta actividad crítica alrededor de Pezoa indica que su obra está viva en la imaginación chilena y que, de continuar, colocará su nombre en el plano más alto de su época. En efecto, no creo exagerado decir que Carlos Pezoa Véliz es el primer poeta chileno moderno. Desde Pedro de Oña hasta la llegada de Rubén Darío a Chile los esfuerzos poéticos chilenos sólo sirvieron para que don Marcelino nos creyera un país sin imaginación. Los contemporáneos de Pezoa han desaparecido de nuestro mundo literario pese al prestigio que tuvieron en vida. Pedro Antonio González, el primer discípulo de Rubén Darío en Chile, ya está completamente "fechado"; también lo está Antonio Bórquez Solar. Un poeta de más méritos, Julio Vicuña Cifuentes, reveló su talento lírico muchos años después de la muerte de Pezoa. Diego Dublé Urrutia, Francisco Contreras, Ernesto Guzmán, tienen su puesto de relativo valor de transición. Sólo Manuel

1. Antologia de Carlos Pezoa Véliz (Santiago de Chile: Ed. Zig-Zag, 1957). (Santiago de Chile: Ed. Nascimento, 1927).

3 Pezoa Véliz, Biografía critica, Antología (Santiago de Chile: Ed. Nascimento, 1951).

* Alma chilena (Santiago-Valparaíso: Impr. Chilena Moderna, 1912). 
Magallanes representa un modernismo más auténtico, pero sus mejores poemas fueron escritos después de la muerte de Pezoa.

Si la obra de Pezoa Véliz sigue presente en la memoria de los chilenos, si se leen sus poemas en nuevas ediciones, si se escriben ensayos acerca de su poesia, debe de haber razones bien fundadas para ello. El caso es más difícil de explicar ya que después de su muerte en 1908 han surgido los mejores poetas de Chile: Manuel Magallanes, Pedto Prado, Gabriela Mistral y Pablo Neruda. Habría sido lógico pensar que la poesía de Pezoa, rodeada de positivos valores, hubiera perdido su estatura y parte de su substancia. No ha sido así, y este proceso histórico nos interesa profundamente. Veamos el caso.

En la obra de Pezoa se ve mejor que en ningún otro poeta chileno ese doble proceso creador del hispanoamericano: lo europeo, más aún francés, de la forma y lo realista, local o regional del tema. Así podemos separar los poemas de Pezoa en dos grupos y mirarlos con un cristal diferente. Es probable que mucho del prestigio logrado por este poeta en los últimos años se deba al carácter sectario de la crítica chilena actual, a la orientación social-económica que dicta sus premisas y postulados. Esta tendencia crítica arbitraria se aplica primero a la novela y luego pasa a la poesía lírica, en los casos de Pablo de Rokha, de Huidobro y de Neruda. En este momento, la poesía de Pezoa, de tono popular, interesada o comprometida es comentada con gran entusiasmo y creemos que la Antología seleccionada por el Sr. Nicomedes Guzmán obedece a esta circunstancia.

Tenemos que formularnos esta pregunta: ¿Representa Pezoa como poeta popular una categoría estética más alta que como poeta modernista? Para contestarla veamos el mérito de sus poemas esencialmente populares: "El organillo", "De vielta de la pampa", "Pancho y Tomás", "Alma chilena". "El organillo" es un poemita romántico, lleno de lugares comunes: relata la nostalgia de un peón que rememora su triste existencia, bajo el influjo de la música de un organillo callejero; en "Alma chilena" Pezoa nos da una descripción del puerto de Valparaíso insertando una historia de sentimentalismo manido y forma prosaica y vulgar. El estilo regional de este poema le aproxima a la concepción poética del Martín Fierro: "Ahí está el "nariz de luna" / que hoy es tiemple de la Ulalia /. (¿y ese rubiote que fuma? / Fue el hijo de un bicbicuma / que importaron de la Australia)".

"De vuelta de la pampa" es otra síntesis de clisés, de prosaísmos, de lugares comunes. El tono moralizante y patriótico raya en lo infantil. Por fin, el poema más conocido de este grupo es "Pancho y Tomás". Esta composición que los críticos consideran como esencia de chilenismo no 
pasa de ser una vulgar relación, un cuento escrito en verso. Es la historia de dos hermanos: "Pancho, el hijo del labriego y su hermano, el buen Tomás". Pancho es el mozo diablo de la mitología popular chilena, el hijo ilegítimo del patrón, alegre, atrevido, garboso:

$$
\begin{aligned}
& \text { y su ademán que perturba, } \\
& \text { y sus ojazos de curva } \\
& \text { noble, su porte, su tez } \\
& \text { son bellos, su frase turba } \\
& \text { ivaya un muchacho cortés! }
\end{aligned}
$$

Notemos, entre paréntesis, el orgullo que siente Pezoa al describir a este personaje, producto de la injusticia económica y social de su patria. Este, Pancho, hijo del señor, es muy superior a su hermano, el hijo del pobre campesino. Pancho se permite engañar a su hermano, el Bueno, y hace de su mujer, Teodora, una adúltera. Por fin, se hace soldado y es feliz. Tomás, carcomido, huraño, traicionado por su mujer, envejece solo, y llora. Tomás el Bueno, en verdad merecería otra suerte, pero Pezoa parece justificar con su fatalismo esta aberración, y lo único que le interesa es el detalle sentimental: "Ni Pancho fue peón de riego / ni su hermano capataz." Aquí nos encontramos frente a un fenómeno "chilenismo". Entre los dos hermanos el "mozo diablo" debe triunfar; el hombre serio, honrado, trabajador, debe fracasar. Las malas cualidades del patrón pasan al hijo, que triunfa; las buenas cualidades del campesino pasan al otro hijo, que fracasa. Lo más triste del caso es la fruición con que el poeta celebra las bellaquerías del hermano malo, con innegable sentimiento de casta.

Este poema sufre de los mismos defectos que los anteriores: una actitud sentimental por demás cursi:

Tomás suspira

en la caída del sol...

¡Pobre Tomás! Pancho toma

fruta de ajena heredad.

¡Pobre! En la vecina loma

se ha perdido una paloma

iAves del bosque, llorad!...

¿Gente pobre, vieja, inculta, mejor es morir... morid!...

Tomás llora

junto a la vieja heredad... 
Un constante deseo de reducir el pensamiento a una fórmula filosófica casera:

$$
\begin{aligned}
& \text { ¡La guerra... morir, matar!... } \\
& \text { ¿Por qué la guerra? La tierra } \\
& \text { no es de Pedro ni es de Juan... }
\end{aligned}
$$

Un desmayado tartamudeo en que la falta de pensamiento le hace decir insulseces y repetir lugares comunes infantiles:

$$
\begin{aligned}
& \text { Luego Tomás se va al lecho } \\
& \text { y el viejo y todos en pos; } \\
& \text { todos miran hacia el techo: } \\
& \text { y las manos en el pecho } \\
& \text { cuentan sus penas a Dios. }
\end{aligned}
$$

O simplemente una falta de secuencia lógica inadmisible en un poeta realista:

$$
\begin{aligned}
& \text { como si eterno desdoro } \\
& \text { le hiciera por siempre andar } \\
& \text { en busca de algo incoloro: } \\
& \text { una bembra, un potrero de oro } \\
& \text { que viera en sueños pasar. }
\end{aligned}
$$

La adjetivación en este poema es casi siempre pleonástica (sargento aguerrido, jilguero campesino, buey manso), a menudo caprichosa (ruidos tristones, errabundo tril, potreros hastiados).

¿En qué se basa entonces la fama de "Pancho y Tomás"? Simplemente en la emoción humana - no artística- del relato. La misma que causaría en el lector si yo dijera: "Teodora, la esposa de Tomás, le engaña con su hermano Pancho, es abandonada por éste y muere. Tomás envejece triste y aban'donado, etc.". Todo esto es penoso pero no tiene relación ninguna con la poesía.

II. Hay que buscar en otro tipo de poesía el mérito esencial de Pezoa Véliz. Esta poesía se puede definir como modernista. El poeta abandona en estos poemas el uso del lenguaje hablado y busca un estilo especial. La voluntad de estilo se manifiesta en él y naturalmente le acerca inmediatamente a la fórmula modernista. El lenguaje literario que usa Pezoa en estas composiciones es el mismo de Darío, Gutiérrez Nájera, Julián del Casal, Silva, Díaz Mirón y Lugones.

Los temas son ahora de limitada selección: orgullo olímpico, tristeza, 
sentimiento de soledad y abandono, amor sensual o petrarquista que se reduce a una combinación de erotismo y misticismo, escenas de la vida de bohemia parisiense y humorismo basado en el uso caprichoso de palabras y frases en francés o inglés.

La influencia de Gutiérrez Nájera es evidente, en especial con "La serenata de Schubert" y "La Duquesa Job", es decir con el tono romántico sentimental y el humorismo parisiense. Como las "mariposas", las "amigas" del poeta mexicano, las "avecillas", las "amigas" de Pezoa, visitan al poeta:

Yo adoro a mis amigas, cuando el sol brilla

llegan en muchachadas a mi bohardilla y me dicen mil cosas que yo adivino en la lengua canora del regio trino.

Ellas, cuando yo muera, irán llorosas a cubrir mi sepulcro de frescas rosas y espiarán a mi virgen en la ventana cuando lea mis versos cada mañana.

("Mis amigas")

La influencia de Gutiérrez Nájeta va estrechamente unida a la del Darío de Prosas profanas. Observemos por ejemplo, el poema "Noctámbula": En algunas estrofas la diáfana atmósfera de la poesía de ensueño, típica del mexicano, queda establecida:

¿Qué dice esa paloma en tu ventana?

"Soy del país donde el ensueño brota, $y$ vengo a vigilar en la mañana

el sueño de una linda compatriota"

peto en ottos es la ardiente inspiración de Darío que se hace presente. Así cuando Pezoa escribe:

¿Quieres probar extraños embelesos?

¿Åmame! Te daré regias primicias,

y un ramo de ígneos y quemantes besos

arrancado al jardín de mis caricias...",

se recuerdan las fogosas frases de Dario:

Flor de gitanas, flor que amor recela, amor de sangre y luz, pasiones locas: flor que trasciende a clavo y a canela, roja cual las heridas y las bocas...

("Divagación"). 
En "Vida de Puerto" Pezoa ha tomado como modelo "La Duquesa Job", no sólo en la forma estrófica idéntica, sino en el aire mundano de enfrentar la poesía en un estilo gracioso e irreverente, lleno de palabras francesas 0 inglesas:

Los dandys que usan chaquet de cola, cuando divisan a su polola guiñan un ojo con sol y sprit. $Y$ un francés cojo, por la platea, con una caja, mientras cojea, dice despacio: ¡Marrons confits!

Sistema que Gutiérrez Nájera usa con mucho más arte que el chileno:

No tiene alhajas mi duquesita: pero es $\tan$ guapa y es tan bonita, y tiene un cuerpo $\tan v^{\prime} l a n, \tan$ pscbutt; de tal manera trasciende a Francia, que no la igualan en elegancia ni las clientes de Hélène Kossut.

("La Duquesa Job")

La influencia de Gutiérrez Nảjera es constante en Pezoa y aparece más precisa en esa poesía de reminiscencias y nostalgia por las cosas idas fatalmente. En "Cansancio del camino", por ejemplo, al lamentar la muerte de su madre, recuerda su vida en familia, como lo hace Gutiérrez Nájera en "La serenata de Schubert":

$Y$ nuestra mesa, los manteles blancos, las copas de color, el vino, el agua; los jarrones pintados con barrancos; carricoches $\mathrm{y}$ bosques de patagua.

Lo ve todo, pero todo eso ya no existe:

$\mathrm{Y}$ veo todo... hasta la parra vieja que aún enarca sus troncos retorcidos, el tordo campesino, la copleja que era el recuerdo de tus tiempos idos. iY todo eso ya hurtado por la muerte! Toda esa dicha que no fué ni mucha... Todo arrancado a la haraposa suerte de un niño sin vigor para la lucha. 
Crea aquí la misma atmósfera de tiempo ido, de muerte, de dicha perdida para siempre, que Gutiérrez Nájera en estas estrofas:

Todo lo vuelvo a ver... iPero no existe!

Todo ha pasado ahora... iY no lo creo!

Todo está silencioso, todo triste...

y todo alegre como entonces veo.

Esta es la casa. ¡Su ventana, aquélla!

Ese, el sillón en que bordar solía...

¡La reja verde... y la apacible estrella

que mis nocturnas pláticas oía!

$Y$ nada existe ya. Calló el piano.

Cerraste, virgencita, la ventana,

y oprimiendo mi mano con tu mano

me dijiste también: "hasta mañana".

Hay también en la poesía de Pezoa frecuentes similitudes con el idealismo altivo de Díaz Mirón. Pueden compararse en este sentido el poema "A Gloria" del mexicano y "Carta a una dama" del chileno. Undurraga, ${ }^{5}$ nota que en 1902 se publica en "La lira chilena" un poema de Díaz Mirón llamado "Ave María", que empieza así:

¡Ave María: Llena de gracia!

Tiene tres lustros, ojos de antílope, mirada de astro, sonrisa de ángel, boca de perlas y de rubíes...

Pezoa lee este poema y lo guarda, y más tarde escribe su composición "Teodorinda", una chica que luce "sus tres gallardos lustros de edad". También hay entre "Ave María" y "Carta a una dama" sospechosos puntos de contacto.

En la constante actitud elegiaca en los poemas de amor hay ecos de José Asunción Silva, como puede observarse en esta estrofa elegida entre muchas:

¿Por qué no la llevaste? yo rezaba en voz baja, y tu risa reía bajo de la mortaja. .

En esa tarde triste que caía de prisa yo sé que se apartaron tu pena y la agria risa, yo sé que en el sepulcro, bajo la noche larga, aún ríe tu cadáver con esa risa amarga; pero sin esa pena que te hacía tan buena, porque jay! yo aquella tarde me volví çon tu pena,

5 Op. cit., p. 208. 
Fue Armando Donoso el primero en observar la influencia del poema "El solterón" de Lugones sobre "Juan Pereza" de Pezoa. ${ }^{6}$ Donoso apunta que en ambos poemas, el solterón y el artista fuman su cachimba, o su pipa, tirados sobre un sofá "mientras ruedan las horas sin desentumecer su ánimo".

Niega esta influencia Antonio Undurraga diciendo que "en 'El Solterón' de Lugones no hay un caso de neurosis del tipo de los dos ya enunciados en sendos poemas de Darío y Pezoa Véliz"? Es posible que el caso de neurosis sea distinto, existiendo en ambos, pero el ambiente creado por los dos poetas es muy semejante. Ambos personajes están fumando su pipa entre acuarelas, tendidos el uno sobre "un mueble inválido" y el otro sobre un "raído sofá"; el pintor Pereza escucha "un reloj viejo que masculla tictac" y el solterón advierte en su calma "Qué cercana está la muerte del silencio del reloj"; uno en su bohardilla "un bostezo larga, y otro, y otro, y tres"; el otro piensa en un lejano duelo y en los disparos, "uno, dos, tres"; Juan Pereza no lee, halla que "Juan Valjean es bruto, necio Tartarín", el solterón, recordando un idilio lejano, dice, "Turgenef tiene uno así"; el solterón "va a escribir una carta a una ajada doncella que le aguarda" y "la carta saldrá mañana", pero "la pluma en sus dedos juega" (es una carta muy antigua y ya está turbio el borrador), y "va llegando la noche, y aún está blanco el papel", y termina "qué mohosa está la pluma, la pluma no escribe ya"; el pintor a su vez piensa escribir a su madre pero "no le escribe nunca porque la pereza le esconde la pluma, la tinta o el block", y en cambio se acuerda en sus cavilaciones de su partida del pueblo en compañía de un recluła y "de una moza flaca de marchita cdad". Termina el poema de Lugones diciendo que "como enturbiada espuma / una idea triste va / emergiendo de su pluma", y en el de Pezoa vemos que el pintor ya no lee nada porque la lectura "anteojos de bruma pone en la nariz".

Al negar la influencia de Lugones el señor Undurraga nos llama la atención acerca del parecido ambiental que existe entre "El pintor Pereza" y "La sonatina" de Darío: "No cabe duda que Rubén Darío, el Rubén de la "Sonatina", es la fuente remota de inspiración de este poema de Pezoa Véliz". 8 Además de la influencia de ambiente Undurraga ve "la medida de la influencia desconocida que ejerció Rubén Darío sobre Pezoa Véliz" en estos dos versos: "la libélula vaga de una vaga ilusión" (Darío) y "que vagan en busca de un vago ideal" (Pezoa). Undurraga en-

- Op. cit., p. 4.

7 Op. cit., p. 253.

8 Ibid., p. 251 . 
cuentra también ecos de "las recetas antineuróticas y antirrománticas" de José Asunción Silva en el poema "Fecundidad" del poeta chileno.

Es evidente que Pezoa Véliz era muy sensible a ciertas vibraciones estéticas comunicadas por espiritus afines. Su estilo poético mejor es, cờmo ya lo hemos dicho, del primer período modernista pero son también discernibles en su poesía, y con frecuencia, notas de Verlaine, de Baudelaire y aun de Edgar Allan Poe. Hace años yo noté esta actitud asimiladora de Pezoa en un artículo en que afirmaba que su famosa elegía "Tarde en el hospital" era una imitación de un poemita de Ada Negri intitulado "Nevicata". Varios críticos chilenos negaron apasionadamente esta posibilidad, tratando de probar que un poeta que yacía enfermo en una cama de hospital y que no sabía italiano mal podía darse el lujo de entregarse a estas lecturas en una lengua extranjera. A pesar de que la elegía de Pezoa es-para mí-su mejor poema, y una creación perfecta de su género, yo sigo creyendo que la semejanza de ambas composiciones es demasiado grande para pensar en una mera coincidencia, en una análoga forma de concebir y de expresar un momento estético. Cito aquí los dos poemas y dejo el juicio último al lector:

\section{Nevicatd}

Sui campi e su le strade silenziosa e lieve, volteggiando, la neve cade.

Danza la falda bianca ne l'ampio ciel scherzosa, poi sul terren si posa stanca.

In mille immote forme sui tetti e sui camini, sui cippi e nei giardini dorme.

Tutto dintorno è pace, chiuso in oblío profondo, indifferente il mondo tace.

Ma ne la calma immensa torna ai ricordi il core, ed al sopito amore pensa. 
Tarde en el bospital

Sobre el campo el agua mustia cae fina, grácil, leve;

con el agua cae angustia:

llueve.

$Y$ pues solo en amplia pieza yazgo en cama, yazgo enfermo, para espantar la tristeza, duermo.

Pero el agua ha lloriqueado junto a mí, cansada, leve; despierto sobresaltado:

llueve.

Entonces, muerto de angustia ante el panorama inmenso, mientras cae el agua mustia pienso.

La poderosa fuerza receptiva de Pezoa coge formas estróficas, ritmos, imágenes, vocabulario, de poesías que le agradan y luego aplica estos elementos a temas muy distintos del original. De aquí sale una rara mezcla de novedad temática y de imitación estilística. Por ejemplo, este mismo poema "Teodorinda" sigue la fórmula de "Del Trópico" de Rubén Darío, poema que Pezoa debe de haber leído; compárense estas estrofas:

Sonriendo a veces a la muchacha, que de la piedra pasa al fogón, un sabanero de buena facha casi en cuchillas afila el hacha sobre una orilla del mollejón.

(Darío)

Si espanta el brío, la airosa facha de la muchacha... iqué floración! Carne bravía, pierna como hacha, anca de bestia, brava muchacha para las hambres de su patrón.

(Pezoa)

En otros dos poemas de Pezoa, "Fecundidad" y "Una astucia de Manuel Rodríguez", se descubre también la nota imitativa. Undurraga ya habia hecho esta observación: "Al leerlo ["Fecundidad"] no podemos 
dejar de pensar en Leconte de Lisle, en Samain, y en ciertos atisbos naturalistas que hay en la obra de Herrera y Reissig, Rubén Darío y otros.". 9 $Y$ da como antecedente de "Una astucia" el poema "San Antonio y el centauro" (I899), de Valencia, en la comparación de estas dos estrofas:

Antonio el cenobiarca del silencioso Egipto, para templar los duelos de su vivir - proscripto en una helada cueva donde retoza el diablomarchóse en altas horas a visitar a Pablo, el más viejo heremita. La paz reinaba en torno; en cálidos efluvios por sus bocas de horno respiraba el desierto. Ya no volaba una sola pareja de íbis rojos. La luna, abriéndose ancho paso tras cenicienta franja, vertía sobre el polvo su amarillo naranja, seguida por un astro. (dorada mariposa que en derredor girase de una pálida rosa).

(Valencia)

Fray Alfonso Guimárez de Medina, el hermano más bonachón y santo del templo franciscano, bajaba por la cuesta con dirección al fondo gloriosamente verde del valle de Aconcagua. El río iba cantando no sé qué cosa en lo hondo de una barranca agreste. Reía abajo el agua con frescachona risa de mujer, con pomposa locuacidad, con esa verbosidad latente con que ríe en la gloria de los campos la rosa a la gloria apacible de la alegre corriente.

(Pezoa)

Yo no sé hasta qué punto esta constante actitud imitativa teste valor a la poesía de Pezoa Véliz. Como su cultura literaria era bastante superficial, adquirida esporádicamente, la refundición de los elementos ajenos no se hace con la perfección o habilidad propia de los imitadores habituales. Pezoa es más original en sus poemas populares, que yo juzgo de calidad inferior. En su manera modernista, a pesar de las influencias, su poesía adquiere una categoría artística, un estilo $\mathrm{y}$, paradójicamente, el sello de su personalidad de literato fiel a su generación. Pezoa es un poeta por demás irregular, un poeta que juzgado en su totalidad, resulta caprichosamente inseguro, oscilando siempre entre la forma prosaica de un realismo antipoético y los balbuceos de un modernismo no siempre bien logrado.

? lbid., p. 226, 
Pero parte de la obra de Pezoa quedará: aquella poesía producto del dolor y de la sinceridad, en que lo popular y lo culto se combinan para expresar al alma de un artista atormentado e intenso: "Tarde en el hospital" y "El pintor Pereza".

Arturo Torres Rioseco, Universidad de California, Berkeley 